\title{
Management of precocious puberty in girls with McCune-Albright syndrome using letrozole
}

\author{
Xi Wang and Qi Yu \\ Department of Obstetrics and Gynaecology, Peking Union Medical College Hospital, Peking Union Medical College and Chinese Academy of Medical \\ Sciences, Beijing, China
}

Correspondence should be addressed to Q Yu: yuqi2008001@sina.com

\begin{abstract}
Objective: To evaluate the safety and efficacy of letrozole in girls with progressive precocious puberty (PP) associated with McCune-Albright syndrome (MAS).

Design: Monocentric retrospective cross-sectional and longitudinal study of consecutive patients.

Patients: Ten MAS patients treated at Peking Union Medical College Hospital between September 1999 and December 2017 were retrospectively reviewed; those with complications due to PP were followed.

Results: The mean age at letrozole initiation was $4.5 \pm 2.6$ years, while the mean duration of treatment was $3.3 \pm 2.4$ years. Letrozole was highly effective at decreasing the rate of skeletal maturation, with a significant decrease in the bone age-to-chronological age (BA/CA) ratio from $1.9 \pm 1.1$ pre-treatment to $1.5 \pm 1.2$ on letrozole treatment $(P=0.016)$. Moreover, growth velocity $Z$-scores declined from $0.41 \pm 0.5$ to $-0.2 \pm 0.31$ with treatment $(P<0.001)$. Predicted adult height $Z$-scores increased significantly from $-2.03 \pm 2.33$ at baseline to $1.13 \pm 0.84$ following treatment initiation $(P=0.029)$. Moreover, vaginal bleeding declined significantly on letrozole.

Conclusions: Our findings suggest that letrozole may be an effective therapy in some girls with MAS, as treatment results in improved BA/CA ratio, growth velocity and predicted adult height. Possible adverse effects include nettle rash.
\end{abstract}

\author{
Key Words \\ - McCune-Albright \\ syndrome \\ - precocious puberty \\ - letrozole \\ - management
}

\section{Introduction}

McCune-Albright syndrome (MAS) is a rare congenital sporadic disorder arising from somatic activating mutations in the GNAS gene. The precise prevalence of MAS is unknown and is estimated to range between $1 / 100,000$ and $1 / 1,000,000(1,2)$. MAS is defined historically as the triad of peripheral precocious puberty (PP), café-au-lait skin pigmentation and fibrous dysplasia (FD) of the bone (3). Other associated hyperfunctioning endocrinopathies include hyperthyroidism, growth hormone excess, phosphate wasting and neonatal hypercortisolism (4). PP is subclassified into peripheral PP (PPP) and central PP (CPP). PPP, which is also known as gonadotropin-releasing hormone ( $\mathrm{GnRH})$-independent
PP, is defined as early pubertal maturation that is not a result of central activation of the hypothalamic-pituitarygonadal axis. CPP, which is GnRH-dependent PP, is based on hypothalamic-pituitary-gonadal axis activation associated with progressive pubertal development, accelerated growth rate and advancement of skeletal age. Symptoms of PP or FD are the most common reasons that patients seek medical support. PP is present in approximately $85 \%$ of female patients with MAS and is often the presenting feature (5). Autonomous activation of ovarian tissue leads to intermittent development of ovarian cysts, resulting in vaginal bleeding upon resolution and subsequent oestrogen withdrawal (c) 2018 The authors Published by Bioscientifica Ltd https://ec.bioscientifica.com

https://doi.org/10.1530/EC-18-0344

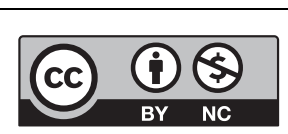

This work is licensed under a Creative Commons Attribution-NonCommercial 4.0 International License. 
$(6,7)$. Girls typically develop progressive PP marked by recurrent vaginal bleeding, increased breast development, accelerated growth velocity and bone age advancement with the potential complication of a significantly shorter adult height (6).

To date, establishing a safe, effective and long-term treatment for PP in girls with MAS has been challenging, and the benefits of current interventions have not been well-established due to the rarity of patients and the heterogeneous nature of the disease. Aromatase inhibitors, which were originally developed for the treatment of oestrogen receptor-positive breast cancer, are relatively newer agents that have been used for the treatment of PP in girls with MAS. The first-generation aromatase inhibitor testolactone was found to have minimal success in the treatment of girls with MAS. One study of seven girls with MAS treated for at least 3 years showed a reduction in both serum oestradiol levels and the frequency of vaginal bleeding. However, the mean predicted adult height (PAH) was not significantly improved after treatment (8). A second-generation aromatase inhibitor, fadrozole, has also been found to have no significant benefit in the treatment of PP in girls with MAS. One study followed 16 girls with MAS treated with fadrozole and found that it does not sufficiently block oestrogen synthesis in most girls with MAS-associated PPP and may impair the adrenocortical stress response (9). A 36-month trial of the third-generation aromatase inhibitor letrozole in ten girls with MAS-associated PP found a significant decrease in the growth velocity standard deviation score and bone age-to-chronological age (BA/CA) ratio as well as cessation or slowing in their rates of bleeding over 12-36 months of therapy (10); however, one girl experienced a ruptured ovarian cyst after 2 years of treatment. To that end, the objective of our study was to evaluate the safety and efficacy of letrozole in girls with progressive PP associated with MAS.

\section{Materials and methods}

This was a single-centre, retrospective analysis of subjects treated at Peking Union Medical College Hospital as part of a long-standing MAS natural history study. The study was approved by the Institutional Review Board of Peking Union Medical College Hospital (Number S-K445). Informed consent was obtained in accordance with the institutional guidelines.

Clinical documents, laboratory data and radiology studies from ten MAS patients treated with letrozole at Peking Union Medical College Hospital between September 1999 and December 2017 were retrospectively reviewed and those with PP were followed. Pre-treatment and on-treatment safety and efficacy measures were evaluated using paired $t$-tests, Wilcoxon matched-pairs and Wilcoxon signed-rank tests. The data were analysed using the R software (R i386 3.4.3.lnk, Bell Laboratory, NJ, USA), and figures were prepared using GraphPad Prism 7 (GraphPad Software). $P$ values $<0.05$ were considered statistically significant. Data are presented as means \pm standard deviations and medians as appropriate depending on the normality of distribution.

\section{Height and skeletal maturation}

Height measurements were performed using a stadiometer and determined as the average of three serial morning values. Bone ages were determined using the Greulich and Pyle method (11); the bone age obtained just prior to letrozole initiation was used as the baseline. When available, bone age and height measurements were used to determine pre-treatment and post-treatment skeletal maturation rates and growth velocities. Height and growth velocity were measured from normative reference data (12).

\section{Pelvic ultrasonography}

Transabdominal pelvic ultrasonography was performed at each evaluation at Peking Union Medical College Hospital. The pelvic ultrasonography finding obtained just prior to letrozole initiation was used as the baseline. Subjects who completed treatment as well as those remaining on treatment underwent pelvic ultrasonography, whereupon uterine volumes were calculated according to the formula: volume $=$ length $\times$ width $\times$ thickness $\times 0.52(13)$.

\section{Results}

\section{Clinical characteristics at baseline}

The ten children included in our study received letrozole treatment for a minimum of 6 months. A diagnosis of MAS was made when at least two of the following cardinal features, based on previously published criteria (5), were present: café-au-lait skin pigmentation, polyostotic/monostotic bone FD and hyperfunctioning endocrinopathies.

The baseline individual clinical characteristics of the ten subjects are summarised in Table 1 . The mean age at
This work is licensed under a Creative Commons Attribution-NonCommercial 4.0 International License. 


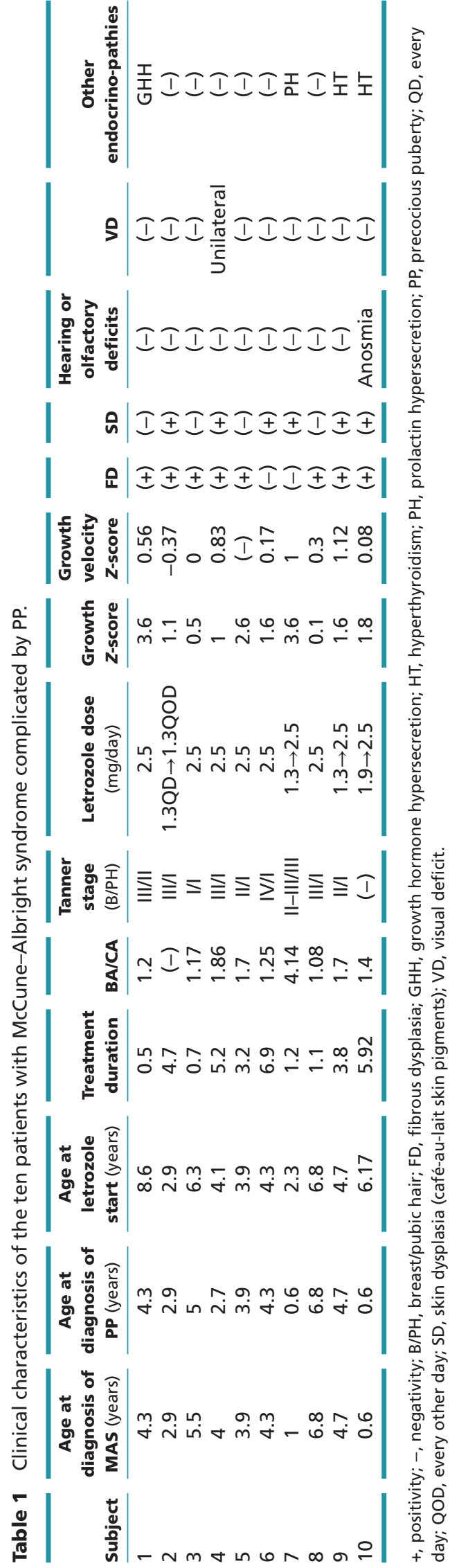

https://ec.bioscientifica.com

https://doi.org/10.1530/EC-18-0344

(C) 2018 The authors Published by Bioscientifica Ltd initial signs of PP was $3.6 \pm 1.9$ years, while the mean age at diagnosis of MAS symptoms was $3.8 \pm 1.9$ years. Eight patients presented with FD; all eight had FD in the limbs and seven also had the condition in craniofacial bones (patients 1, 2, 3, 4, 6, 9 and 10). One patient developed anosmia (subject 10), one had bilateral neural tube stenosis (subject 1) and two had involvement of the axial skeleton (subjects 6 and 8). FD in the extremities usually presented with a pathological fracture (subject 9), three had hip bone involvement (subjects 1, 2, and 4) and one experienced limping (subject 2). Six patients had skin dysplasia. Subject 4 experienced visual deficit, and subject 1 developed growth hormone hypersecretion. Subjects 2, 6, 9, and 10 (i.e., $40 \%$ of patients) showed functional and/or morphological thyroid abnormalities, and subjects 9 and 10 (i.e., 20\%) had clinical hyperthyroidism.

Subjects 1 and 3 had received previous treatment for PP prior to starting letrozole; the former had experienced elevated levels of oestradiol $\left(\mathrm{E}_{2}\right)$ while the latter had continuous vaginal bleeding (Table 1). These therapies were discontinued at or shortly after letrozole initiation. Tamoxifen was administered to patient 1 as an adjuvant therapy owing to unabated vaginal bleeding after initiating letrozole. Four girls were receiving a GnRH analogue, as they subsequently developed CPP from PPP.

\section{Letrozole initiation and treatment duration}

The mean age at letrozole initiation was $4.5 \pm 2.6$ years. The letrozole dose differed between subjects. Six patients from the initial letrozole pilot study were dosed according to the parameters of that study (a single $2.5 \mathrm{mg}$ dose once daily), three subjects shifted to a single $2.5 \mathrm{mg}$ dose once daily from $1.25 \mathrm{mg}$ or $1.88 \mathrm{mg}$ dose once daily with pubertal progression and one subject reduced dosing from a single daily $1.25 \mathrm{mg}$ dose every day to the same dose every other day after experiencing pubertal remission (Table 1). The mean duration of treatment was $3.3 \pm 2.4$ years.

\section{Growth change}

The subjects' mean BA/CA ratio, growth Z-score and growth velocity $Z$-score were significantly decreased after treatment. Data on bone ages pre-treatment, at baseline (start of letrozole therapy) and during treatment were available for six subjects; the values were used to determine the pre- and on-treatment BA/CA ratio. There was a significant decrease in the $\mathrm{BA} / \mathrm{CA}$ ratio

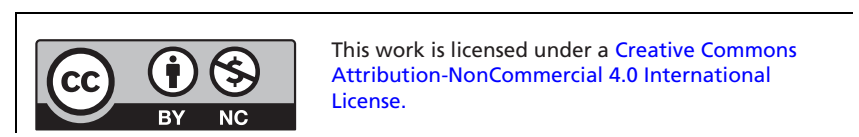



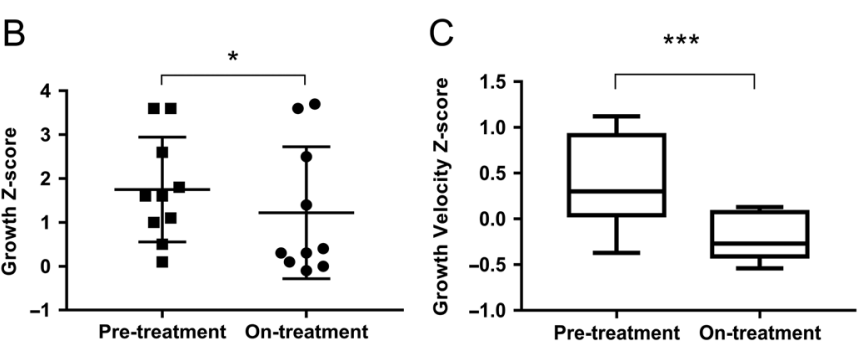

Figure 1

Letrozole effects on bone age-to-chronological age (BA/CA) ratio, growth Z-score and growth velocity Z-score. There was a significant decrease in the $\mathrm{BA} / \mathrm{CA}$ ratio (panel $\mathrm{A},{ }^{*} P=0.016$ ), growth $Z$-score (panel $\mathrm{B},{ }^{*} P=0.02$ ) and growth velocity $Z$-scores (panel $\mathrm{C}, * * * P<0.001$ ) over the course of the treatment.

from a pre-treatment mean value of $1.93 \pm 1.12$ to an on-treatment mean value of $1.51 \pm 1.23(P=0.016)$ after initiating letrozole (Fig. 1A and Table 2). Pre-treatment and on-treatment growth $Z$-scores as well as growth velocity $Z$-scores were available for all ten subjects; the growth $Z$-score decreased significantly from a pretreatment mean of $1.69 \pm 1.1$ to an on-treatment mean of $1.04 \pm 1.1(P=0.02)$ (Fig. $1 \mathrm{~B}$ and Table 2$)$. There was a significant decrease in the growth velocity $Z$-score following letrozole treatment, from a pre-treatment mean of $0.41 \pm 0.5$ to $-0.2 \pm 0.31$ on treatment (Fig. 1C and Table $2, P<0.001$ ).

\section{PAH}

PAH Z-scores were determined for four subjects, concluding the subject 1 for the complication of GHH, pre- and on-treatment according to previously described methods (14). There was a significant increase over the letrozole treatment period from $-2.03 \pm 2.33$ at baseline to $1.13 \pm 0.84$ on-treatment $(P=0.029)$ (Fig. 2 and Table 2$)$.

\section{Uterine volumes}

Pre- and on-treatment pelvic ultrasonography data were available for eight subjects. There was no change in median uterine volumes over the letrozole treatment period $\left(7.3 \pm 3.2 \mathrm{~cm}^{3}\right.$ to $7.5 \pm 5.5 \mathrm{~cm}^{3}(P=0.56)$ (Table 2)). Since only the lengths and widths of the ovaries could be obtained, the ovarian volumes could not be calculated accurately.

\section{Hormone levels}

Pre- and on-treatment oestradiol levels were available for all the subjects. Given the episodic nature of oestradiol production in MAS, pre-treatment values varied in range from $2.5 \mathrm{pg} / \mathrm{mL}$ to $700 \mathrm{pg} / \mathrm{mL}$ (median, $182 \pm 264 \mathrm{pg}$ / $\mathrm{mL})$. These levels were reduced following the initiation of letrozole treatment and ranged between $2.5 \mathrm{pg} / \mathrm{mL}$ and $78.4 \mathrm{pg} / \mathrm{mL}$ (median $19 \pm 29 \mathrm{pg} / \mathrm{mL}$ ); this change was significant according to a unilateral $t$-test of the decline of oestradiol levels $(P=0.033)$ (Fig. 3 and Table 3$)$. Pretreatment serum alkaline phosphatase levels of $557 \mathrm{U} / \mathrm{L}$

Table 2 Response to letrozole therapy in ten girls with precocious puberty and polyostotic fibrous dysplasia of the bone due to McCune-Albright syndrome.

\begin{tabular}{|c|c|c|c|c|c|c|c|c|c|c|}
\hline Subject & BA/CA (pre) & BA/CA (on) & $\begin{array}{c}\text { Uterine } \\
\text { volumes } \\
\text { (pre) }\end{array}$ & $\begin{array}{l}\text { Uterine } \\
\text { volumes } \\
\text { (on) }\end{array}$ & $\begin{array}{l}\text { Growth } \\
\text { Z-score } \\
\text { (pre) }\end{array}$ & $\begin{array}{l}\text { Growth } \\
\text { Z-score } \\
\text { (on) }\end{array}$ & $\begin{array}{c}\text { Growth } \\
\text { velocity } \\
\text { Z-score (pre) }\end{array}$ & $\begin{array}{c}\text { Growth } \\
\text { velocity } \\
\text { Z-score (on) }\end{array}$ & $\begin{array}{c}\text { PAH (cm) } \\
\text { Z-score (pre) }\end{array}$ & $\begin{array}{c}\text { PAH (cm) } \\
\text { Z-score (on) }\end{array}$ \\
\hline 1 & 1.2 & 1.09 & 9.6 & 10 & 154 (3.6) & $157(1.7)$ & 0.56 & 0.05 & $177.3(3.2)$ & $182.6(4.2)$ \\
\hline 2 & Null & 1 & 7.3 & 1.1 & $97.5(1.1)$ & $124(0.4)$ & -0.37 & -0.33 & Null & Null \\
\hline 3 & 1.17 & Null & 7.5 & Null & $119(0.5)$ & $123(0.3)$ & 0 & -0.54 & Null & Null \\
\hline 4 & 1.86 & 0.84 & 2.9 & 3.3 & $106(1)$ & $134.7(0)$ & 0.83 & -0.08 & $131.8(-5.4)$ & $170.4(1.8)$ \\
\hline 5 & 1.7 & 1.1 & 6.7 & 2.7 & $113(2.6)$ & $136.5(2.7)$ & Null & 0.05 & $151.6(-1.7)$ & 170.9 (1.9) \\
\hline 6 & 1.25 & 1 & 13.5 & 11.6 & $137(1.6)$ & $150(-0.1)$ & 0.17 & -0.4 & $159(-0.3)$ & $162.6(0.4)$ \\
\hline 7 & 4.14 & 4 & 7.6 & 10.7 & $101(3)$ & $113(3.7)$ & 1 & 0.13 & Null & Null \\
\hline 8 & 1.08 & Null & 11.2 & Null & $120(0.1)$ & $127(0.1)$ & 0.3 & -0.27 & Null & Null \\
\hline 9 & 1.7 & Null & 4.3 & 3.6 & $116(1.6)$ & 139.5 (1.4) & 1.12 & 0.1 & Null & Null \\
\hline 10 & 1.4 & 1 & 6.3 & 16.6 & $125.6(1.8)$ & $147(0.1)$ & 0.08 & 0.42 & $156.7(-0.7)$ & $162.6(0.4)$ \\
\hline
\end{tabular}

$\mathrm{BA} / \mathrm{CA}$, bone age-to-chronological age ratio; on, on treatment; $\mathrm{PAH}$, predicted adult height; pre, pre-treatment.

$$
\begin{aligned}
& \text { https://ec.bioscientifica.com } \\
& \text { https://doi.org/10.1530/EC-18-0344 } 2018 \text { The authors }
\end{aligned}
$$




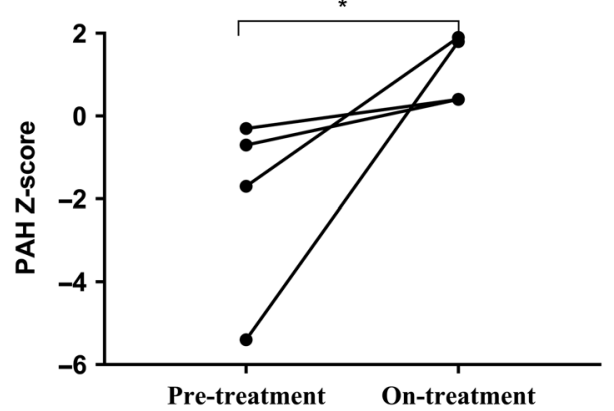

Figure 2

Predicted adult height (PAH) Z-scores before and after letrozole treatment. There was a significant increase in the PAH $Z$-score over the treatment period. ${ }^{*} P=0.029$

dropped to $434 \mathrm{U} / \mathrm{L}$ following treatment (Table 3, $P=0.019)$. There were no significant changes in the levels of luteinising hormone, follicle-stimulating hormone, insulin-like growth factor 1, testosterone or prolactin owing to treatment (Table $3, P>0.05$ ).

\section{Vaginal bleeding and pubertal staging}

Pre- and on-treatment vaginal bleeding frequency data were available for all ten subjects. Among the girls who experienced this condition before therapy, vaginal bleeding occurred at a median frequency of 5.9 episodes per year (range 0-12). This frequency declined significantly following letrozole treatment, with eight subjects experiencing no bleeding episodes and one experiencing a single bleeding episode per year.

Pubertal stages of breasts and pubic hair stabilised during the treatment period (I-IV and I-III, respectively, before therapy vs I-V and I-III, respectively, after initiating treatment).

Subjects were also monitored for CPP, which typically develops in children with treated or untreated PPP.

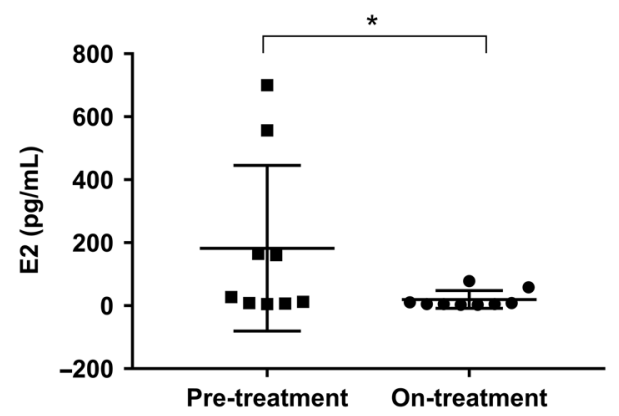

Figure 3

Oestradiol levels before and after letrozole treatment. There was a significant decrease in oestradiol levels over the treatment period. * $P=0.033$.

$$
\begin{array}{lr}
\text { https://ec.bioscientifica.com } & \text { ○ } 2018 \text { The authors } \\
\text { https://doi.org/10.1530/EC-18-0344 } & \text { Published by Bioscientifica Ltd }
\end{array}
$$

None of the subjects had CPP at baseline; however, subjects 5, 7, 9 and 10 subsequently entered central puberty while on letrozole. The mean chronologic age and bone age upon entrance into central puberty were $8.75 \pm 0.96$ (range 6-8) years and $7.43 \pm 1.82$ (range $8-10$ ) years, respectively. Subjects with central puberty were treated with GnRH analogue therapy.

\section{Adverse effects during treatment}

Patient 6 complained of repeated nettle-rash during the first 3 months of treatment; this resolved spontaneously within 1 year. None of the other patients developed any specific adverse events.

\section{Discussion}

PP is the most common endocrinopathy in individuals with MAS. PP affects girls more often than boys, with vaginal bleeding being the initial manifestation. Autonomic activation of ovarian tissue leads to ovarian follicular cysts and elevated oestrogen levels. This status is defined as PPP since the hypothalamic-pituitary-gonadal axis is inactive, although progression to CPP may occur during follow-up $(15,16)$. Despite therapeutic advances, the treatment of MAS-associated PP remains challenging. Early reports of the first-generation aromatase inhibitor testolactone showed no sustained beneficial effects on skeletal growth or maturation $(8,17)$. The second-generation agent fadrozole was also found to block oestrogen synthesis insufficiently in most girls with MAS-associated PPP and possibly impaired the adrenocortical stress response (18). The most potent third-generation aromatase inhibitor, letrozole, had mixed results $(19,20)$. Feuillan et al. (21) performed a preliminary 3-year study of letrozole and reported that letrozole could be used as an alternative therapy for girls with MAS based on a decreased rate of skeletal maturation. In our retrospective cohort study, letrozole treatment was found to have beneficial effects on vaginal bleeding, skeletal maturation, growth velocity and PAH in girls with MAS-associated PP. Compared with pre-treatment oestradiol levels, on-treatment levels were significantly reduced from $182 \pm 264 \mathrm{pg} / \mathrm{mL}$ to $19 \pm 29 \mathrm{pg} / \mathrm{mL}$. These findings were consistent with those of a previous study by Estrada et al. (22).

We found that letrozole is an effective treatment for MAS-associated PP and is well tolerated with no severe adverse events, no increase in uterine volumes and no additional cases of torsion during the treatment

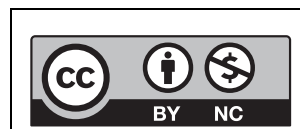

This work is licensed under a Creative Commons Attribution-NonCommercial 4.0 International License. 


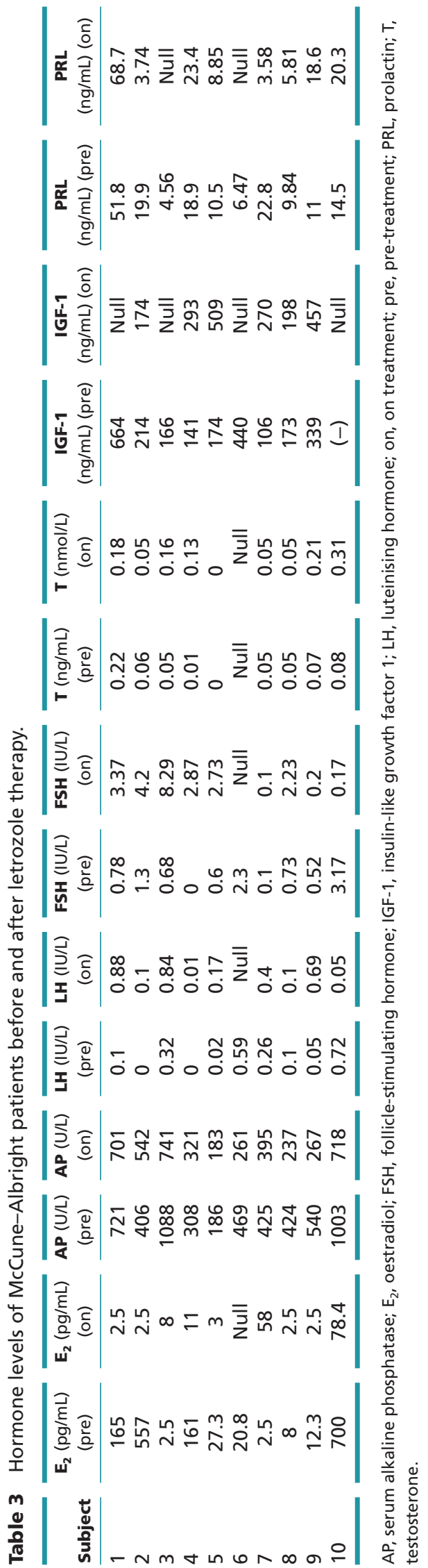

https://ec.bioscientifica.com

https://doi.org/10.1530/EC-18-0344

C 2018 The authors Published by Bioscientifica Ltd or follow-up period. Other therapies have also been previously described. Fulvestrant, which binds to and rapidly degrades the oestrogen receptor, was found to be moderately effective in decreasing vaginal bleeding and the rate of skeletal maturation in girls with PPP over a 1 -year period without causing uterine alterations or other serious adverse events (23). Our study indicates that letrozole may be an effective and relatively safe treatment for girls with PPP, offering an alternative therapy for those who fail to respond to oestrogen blockers such as tamoxifen.

Thyroid disorder is the second most common endocrinopathy in MAS (24), although there is no agreement regarding the frequency or the peculiarities of thyroid abnormalities. Involvement of the thyroid gland is a common and sometimes overlooked feature of MAS. Although thyroid cancer has been described in two patients with MAS, the prevalence of malignancy does not appear to be high (25). A retrospective polycentric study of 36 MAS patients over 20 years found that the prevalence of thyroid alterations was $31 \%$; 7 of 11 patients with thyroid alterations had nodular goitres, with nodules $>1 \mathrm{~cm}$ (26). In our study, four patients (40\%) showed functional and/or morphological thyroid abnormalities, and two (20\%) had clinical hyperthyroidism with treatment. A strict monitoring of thyroid function is recommended every 6 months (26). FD is the most common feature of MAS (27) and can involve the craniofacial bones (28). Eight patients in our study had polyostotic FD, seven of whom had both limb and craniofacial bone involvement.

The diagnosis of MAS is primarily clinical and radiological; although bone histology and genetic analysis do confirm the diagnosis, these are seldom required to confirm it (29). The relative prevalence of the café-aulait spots in a previously described Korean cohort of 14 patients with MAS followed over 16 years was 64\% (30). Similarly, café-au-lait spots were found in six of our ten patients (60\%). Such skin pigmentation results from an activating mutation of melanocyte $\mathrm{G}(\mathrm{s})$ alpha and appears to be linked to tyrosinase gene production via cyclic adenosine monophosphate signalling (31).

The ultimate outcome of interest in the treatment of PP is adult height; this requires extended follow-up times and is therefore rarely reported, particularly in rare disorders such as MAS. Despite the small sample size, letrozole treatment resulted in a statistically significant decrease in the BA/CA ratio, growth $Z$-score and growth velocity, as well as an increase in $\mathrm{PAH}$, leading to an increased adult height; these data further support the efficacy of this therapy.

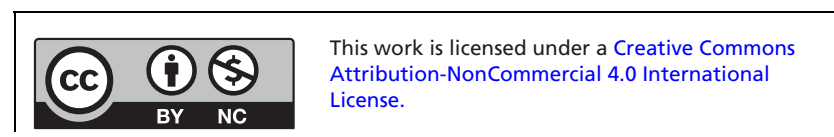


There were several limitations to our study. MAS is rare, and a very limited number of patients have received letrozole therapy; thus, data from an untreated control group of subjects were not available, and each subject served as her own control. However, the inclusion of patient data spanning 18 years enabled studying a reasonable sample size and generated statistically significant results. Notably, the study was also limited by the inherent disadvantages of retrospective analyses. Growth outcomes in MAS are complex and may be affected by multiple confounders such as skeletal deformities and other endocrinopathies. The latter include hyperthyroidism and growth hormone excess, which may accelerate growth, as well as Cushing syndrome, which may decelerate growth. All inherent endocrinopathies were assessed in our patients and managed medically. Further studies with a greater number of patients who completed treatment and reached skeletal maturity are required to confirm the effect of letrozole on adult height.

\section{Declaration of interest}

The authors declare that there is no conflict of interest that could be perceived as prejudicing the impartiality of the research reported.

\section{Funding}

This work did not receive any specific grant from any funding agency in the public, commercial, or not-for-profit sector.

\section{Acknowledgments}

The authors are grateful to all the patients and the families in this study for their collaboration.

\section{References}

1 Dumitrescu CE \& Collins MT. McCune-Albright syndrome. Orphanet Journal of Rare Diseases 20083 12. (https://doi.org/10.1186/17501172-3-12)

2 Weinstein LS, Shenker A, Gejman PV, Merino MJ, Friedman E \& Spiegel AM. Activating mutations of the stimulatory $\mathrm{G}$ protein in the McCune-Albright syndrome. New England Journal of Medicine 1991 325 1688-1695. (https://doi.org/10.1056/NEJM199112123252403)

3 Albright F, Butler AM, Hampton AO \& Smith P. Syndrome characterized by osteitis fibrosa disseminata, areas of pigmentation and endocrine dysfunction, with precocious puberty in females. New England Journal of Medicine 1937216 727-746. (https://doi. org/10.1056/NEJM193704292161701)

4 Brillante B, Guthrie L \& Van Ryzin C. McCune-Albright syndrome: an overview of clinical features. Journal of Pediatric Nursing 201530 815-817. (https://doi.org/10.1016/j.pedn.2015.06.009)

5 Boyce AM \& Collins MT. Fibrous dysplasia/McCune-Albright syndrome. In Gene Reviews®, pp 1993-2018. Eds RA Pagon, MP Adam \& HH Ardinge. Seattle, WA: University of Washington, 2015.

6 Haddad N \& Eugster E. An update on the treatment of precocious puberty in McCune-Albright syndrome and testotoxicosis. Journal of
Pediatric Endocrinology and Metabolism 200720 653-661. (https://doi. org/10.1515/JPEM.2007.20.6.653)

7 Foster CM, Feuillan P, Padmanabhan V, Pescovitz OH, Beitins IZ, Comite F, Shawker TH, Loriaux DL \& Cutler GB. Ovarian function in girls with McCune-Albright syndrome. Pediatric Research 198620 859-863. (https://doi.org/10.1203/00006450-198609000-00010)

8 Feuillan PP, Jones J \& Cutler GB Jr. Long-term testolactone therapy for precocious puberty in girls with the McCune-Albright syndrome. Journal of Clinical Endocrinology and Metabolism 199377 647-651. (https://doi.org/10.1210/jcem.77.3.8370686)

9 Nunez SB, Calis K, Cutler GB Jr, Jones J \& Feuillan PP. Lack of efficacy of fadrozole in treating precocious puberty in girls with the McCuneAlbright syndrome. Journal of Clinical Endocrinology and Metabolism 200388 5730-5733. (https://doi.org/10.1210/jc.2003-030864)

10 Feuillan P, Calis K, Hill S, Shawker T, Robey PG \& Collins MT. Letrozole treatment of precocious puberty in girls with the McCuneAlbright syndrome: a pilot study. Journal of Clinical Endocrinology and Metabolism 200792 2100-2106. (https://doi.org/10.1210/jc.20062350)

11 Wingate Todd T. Radiographic atlas of skeletal development of the hand and wrist based on the brush foundation study of human growth and development initiated. JAMA 19501431124.

$12 \mathrm{Li} \mathrm{H}$, Ji CX, Zong XN \& Zhang YQ. Height and weight standardized growth charts for Chinese children and adolescents aged 0 to 18 years. Zhonghua Er Ke Za Zhi 20097 487-492.

13 Goldberg BB \& Mcgahan JP. Atlas of Ultrasound Measurements, 2nd ed. Philadelphia, PA: Mosby Elsevier, 2006.

14 Bayley N \& Pinneau SR. Tables for predicting adult height from skeletal age: revised for use with the Greulich-Pyle hand standards. Journal of Pediatrics 195240 423-441. (https://doi.org/10.1016/ S0022-3476(52)80205-7)

15 Mieszczak J \& Eugster EA. Treatment of precocius puberty in McCune-Albright syndrome. Pediatric Endocrinology Reviews 20074 419-422.

16 Matarazzo P, Lala R, Andreo M, Einauidi S, Altare F, Viora E, Buzi F, De Luca F, De Sanctis V, Rigon F, et al. McCune-Albright syndrome: persistence of autonomous ovarian hyperfunction During adolesance and early adult age. Endocrinology and Metabolism 200619 607-617.

17 Feuillan PP, Foster CM, Pescovitz OH, Hench KD, Shawker T, Dwyer A, Malley JD, Barnes K, Loriaux DL \& Cutler GB Jr. Treatment of precocious puberty in the McCune-Albright syndrome with the aromatase inhibitor testolactone. New England Journal of Medicine 1986315 1115-1119. (https://doi.org/10.1056/ NEJM198610303151802)

18 Nunez SB, Calis K, Cutler GB Jr, Jones J \& Feuillan PP. Lack of efficacy of fadrozole in treating precocious puberty in girls with the McCuneAlbright syndrome. Journal of Clinical Endocrinology and Metabolism 200388 5730-5733. (https://doi.org/10.1210/jc.2003-030864)

19 Azim AA, Costantini-Ferrando M, Lostritto K \& Oktay K. Relative potencies of anastrozole and letrozole to suppress estradiol in breast cancer patients undergoing ovarian stimulation before in vitro fertilization. Journal of Clinical Endocrinology and Metabolism 200792 2197-2200. (https://doi.org/10.1210/jc.2007-0247)

20 Mieszczak J, Lowe ES, Plourde P \& Eugster EA. The aromatase inhibitor anastrozole is ineffective in the treatment of precociouspuberty in girls with McCune-Albright syndrome. Journal of Clinical Endocrinology and Metabolism 200893 2751-2754. (https:// doi.org/10.1210/jc.2007-2090)

21 Feuillan P, Calis K, Hill S, Shawker T, Robey PG \& Collins MT. Letrozole treatment of precocious puberty in girls with the McCuneAlbright syndrome: a pilot study. Journal of Clinical Endocrinology and Metabolism 200792 2100-2106. (https://doi.org/10.1210/jc.20062350)

22 Estrada A, Boyce AM, Brillante BA, Guthrie LC, Gafni RI \& Collins MT. Long-term outcomes of letrozole treatment for precocious puberty in girls with McCune-Albright syndrome.
This work is licensed under a Creative Commons Attribution-NonCommercial 4.0 International License. 
European Journal of Endocrinology 2016175 477-483. (https://doi. org/10.1530/EJE-16-0526)

23 Sims EK, Garnett S, Guzman F, Paris F, Sultan C, Eugster EA \& Fulvestrant McCune-Albright Study Group. Fulvestrant treatment of precocious puberty in girls with McCune-Albright syndrome. International Journal of Pediatric Endocrinology 20122012 26. (https:// doi.org/10.1186/1687-9856-2012-26)

24 Mastorakos G, Mitsiades NS, Doufas AG \& Koutras DA. Hyperthyroidism in McCune-Albright syndrome with a review of thyroid abnormalities sixty years after the first report. Thyroid $1997 \mathbf{7}$ 433-439. (https://doi.org/10.1089/thy.1997.7.433)

25 Congedo V \& Celi FS. Thyroid disease in patients with McCuneAlbright syndrome. Pediatric Endocrinology Reviews 20074 (Supplement 4) 429-433.

26 Tessaris D, Corrias A, Matarazzo P, De Sanctis L, Wasniewska M, Messina MF, Vigone MC \& Lala R. Thyroid abnormalities in children and adolescents with McCune-Albright syndrbome. Hormone Research in Paediatrics 201278 151-157. (https://doi. org/10.1159/000342641)

27 Collins MT, Singer FR \& Eugster E. McCune-Albright syndrome and the extraskeletal manifestations of fibrous dysplasia. Orphanet
Journal of Rare Diseases 20127 (Supplement 1) S4. (https://doi. org/10.1186/1750-1172-7-S1-S4)

28 Couturier A, Aumaître O, Gilain L, Jean B, Mom T \& André M. Craniofacial fibrous dysplasia: a 10-case series. European Annals of Otorhinolaryngology, Head and Neck Diseases 2017134 229-235. (https://doi.org/10.1016/j.anorl.2017.02.004)

29 Majoor BC, Appelman-Dijkstra NM, Fiocco M, van de Sande MA, Dijkstra PS \& Hamdy NA. Outcome of long-term bisphosphonate therapy in McCune-Albright syndrome and polyostotic fibrous dysplasia. Journal of Bone and Mineral Research 201732 264-276. (https://doi.org/10.1002/jbmr.2999)

30 Cho EK, Kim J, Yang A, Ki CS, Lee JE, Cho SY \& Jin DK. Clinical and endocrine characteristics and genetic analysis of Korean children with McCune-Albright syndrome: a retrospective cohort study. Orphanet Journal of Rare Diseases 201611 113. (https://doi. org/10.1186/s13023-016-0496-x)

31 Kim IS, Kim ER, Nam HJ, Chin MO, Moon YH, Oh MR, Yeo UC, Song SM, Kim JS, Uhm MR, Beck NS \& Jin DK. Activating mutation of GS alpha in McCune-Albright syndrome causes skin pigmentation by tyrosinase gene activation on affected melanocytes. Hormone Research 199952 235-240. (https://doi.org/10.1159/000023467)

\section{Received in final form 15 October 2018}

Accepted 20 November 2018

Accepted Preprint published online 22 November 2018
This work is licensed under a Creative Commons Attribution-NonCommercial 4.0 International License. 